\title{
Chinese Class Construction based on Professional Communication Skill Training in Higher Vocational Institutes
}

\author{
Zhang Ting
}

\begin{abstract}
Vocational key skill has gradually become the basic ability for people to achieve success, among which professional communication skill is the basis. University Chinese, as an important course for higher vocational colleges conducting quality education, is able to train students in terms of communication ability. Based on this, this paper analyzes the Chinese class construction based on professional communication skill training in higher vocational institutes.
\end{abstract}

Keywords-Vocational Key Skills; Communication Ability; University Chinese

\section{THE NECESSITY OF UNIVERSITY STUDENTS MASTERING PROFESSIONAL COMMUNICATION ABILITY}

\section{A. Professional core competence}

In the post-industrial society dominated by service, people profoundly realize that there is a more important one besides professional abilities for people to achieve success. Academic proficiency and expertise can achieve success in the position while other abilities can grant people with more opportunities. Professor Mertens, the director of German labor market and professional institute put forward the idea of key skills in 1972 after carrying out studies on basic skills of people for a long time, which is quickly recognized by the globe. For example, in the United Kingdom there is a training and certification system cultivating the key skills in terms of six models such as communication, cooperation, and self-management; in America, the secondary primary schools offer the communication and self-management courses. In addition, USA Department of Education, the Education Department of various states, NOCTI also come up with the idea of soft skills (also known as basic skill) training evaluation system, which includes eight models such as communication and team work.

We call the ability professional key skills, which can be beckoned as the basic one and can be applicable to any period.

The research conducted by Professor Wu Zhen studying on Structure, Evaluation and Promotion of Chinese Labors' Professional Key Skills indicate that the key skills are constituted by verbal expression skills, communication skills, information collecting and processing technique, self-improvement and self-management.

B. Professional communication ability has gradually become significant key skill

Marx considered that the essence of man was the ensemble of social relations and the development of an individual decides the development of the people he directly or indirectly socializes with. People are social creatures as well as products created by the interaction among people.

Yeb Sheng-tao once said that language is an essential tool for people to communicate and those who are not good at using this tool cannot work and live or even act as a man.

The researches carried out by a glittering array of institutes indicate that over $70 \%$ problems do not come from professional fields because of poor communication.

Therefore, we can see that communication ability is mandatory competence for people to survive and develop, especially in the knowledge-based economy with highly developed information technology. Effective professional communication ability has become one of the important issue to evaluate high-quality people and people who are equipped with communication ability find the access to success.

Based on this, the major project National Rejuvenation Strategy of Skills conducted by Ministry of Labor and Social Security puts forward eight key skills and communication skill stands first on the list. What's more, the CVCC also puts forward that communication skill is the core, which is the basis of professional key skills.

C. The real condition in higher vocational school asks urgently to improve the professional communication ability of students

In general, higher vocational students have a weak cultural foundation without excellent comprehensive quality and they are not confident in communicating with others. At present, China is experiencing great changes and transformation, asking higher demand on talents and the employment pressure is increasing. Higher vocational colleges students have lower base without competence. Therefore, in order to remain invincible in the fierce competition environment, the professional key skills shall be the key for them to achieve success.

In this context, it is imperative and necessary to carry out communication education on students in higher vocational school.

\section{THE POSSIBILITY TO CARRY OUT PROFESSIONAL COMMUNICATION SKILL TRAINING IN UNIVERSITY CHINESE CLASS}

The Chinese class in higher vocational school is being marginalized and its reason is that teacher teaches 
for teaching. In higher vocational schools, skill cultivation is highlighted and it is undesirable to turn university Chinese into advanced Chinese lesson comparing to the high school class or literature appreciation class.

Chinese is a unique discipline, integrating humanity, aesthetic appreciation and instrumentality, which cannot only improve students' oral and written ability but also enrich their cultural, moral and aesthetic appreciation. Therefore, the Chinese class in higher vocational school should switch the targets and turn traditional Chinese teaching into a class of comprehensive cultivation. What's more, a combination point should be found out in the professional quality framework so as to integrate it with professional quality combination to cultivate students' soft ability and combine their professional communication with communication ability cultivation.

In practical teaching, university Chinese class should aim to cultivate students' comprehensive quality such as the language ability improvement (including written and oral language), and humanity quality shaping so as to take advantage of the humanistic, aesthetic and instrumental features, demonstrating the real charm of university Chinese course.

Professional communication ability includes written communication, oral communication and non-verbal elements, which is the concentrated exposure of language expression as well as the comprehensive demonstration of individual quality and is closely related to university Chinese class because both of them can learn language literature. The university Chinese class enables students to be exposed to the classic literature works, which can cultivate their humanity qualities and help them grasp the language skill. In addition, it can also cultivate students' oral expression skill and communication strain capacity.

\section{UNIVERSITY CLASS CONSTRUCTION BASED ON PROFESSIONAL COMMUNICATION ABILITY TRAINING}

Professional communication includes written communication, oral communication and nonverbal communication and therefore, the university Chinese class should pay attention to the above three points to make students open their mouth, put pen to paper and listen attentively to feel. Based on this, it aims to make students communicate properly with quality and efficiency.

\section{A. It cannot separate from the tradition and should lay the professional communication ability foundation based on traditional text reading}

University Chinese class is offered for those with knowledge base, independent thinking ability as well as social consciousness and if the Chinese class in higher vocational school only emphasizes the instrumentality and takes listening, speaking, reading, writing as the objectives, it is sacrificing the substance for the shadow. $\mathrm{Xu}$ Hui, the director of arts of Higher Education Department of Education Ministry once pointed out that in universities, quality education largely depends on Chinese class teaching. Therefore, the humanity and aesthetic appreciation cannot be ignored because in essence, students do not study the language in Chinese class, yet they learn the ability to construct their mental world. (Zhu Ziqiang)

So, university Chinese teaching cannot separate from traditional tasks, and classic literature works reading is also necessary so as to cultivate the humanity qualities, strengthen their perception ability, which can be beckoned as the base for professional communication ability cultivation.

Classic literature reading can integrate the profound ideas with real life so as to make it easy for students to understand the contents and help students extract the essence of worldwide famous literatures, being exposed to the world civilization. Based on this, students can think, percept and rich their life experience, improve humanity quality, expand their horizon and enrich the soul. Pan Chouyuan, a famous educator once said that the knowledge of humanities must be transferred into humanity spirit, showing in behaviors to construct stable quality structure. When students get mature, with rational thought and perfect morality, they are equipped with non-verbal elements in the course of communication, including confident attitude, attentive listening, proper appreciation and tolerance when there is a battle.

Extensive classic text reading grants students with a good basis, which can also cultivate their understanding ability, perception ability and demonstration ability in the course of professional communication. In addition, they can correctly write and demonstrate accurately, which can to some extent change their errors and improper words using, unclear demonstration etc.

\section{B. Enrich the oral skill training and improve the oral communication ability based on reading}

Giving a class is not enough to help students learn the essence of classic literatures, and the most important is reading, that is to say to clearly and emotionally read the textbooks with dynamic demonstration. Zhu Guangqian, master of Esthetics once said that to read again and again until one knows by heart requires people to recite frequently and clearly understand the meaning, the sound and beats of each word, which tells the essence of reading.

Reading is the most direct, frequent and important approach to cultivate and strengthen students' appreciation ability. A dazzling array of reading can cultivate students with sensitive ability, which can improve their understanding ability and enhance their aesthetic taste.

In middle and primary schools Chinese teaching classes, teachers always pay attention to reading training. After being recruited by universities, students have richer life experience as well as sensitive emotional feelings. Yet the best approach to help students feel the language charm is always being ignored by teachers.

Good communication ability should be supported by powerful language perception ability and it is necessary to conduct long-term and regulated training. At the same time, techniques such as order of priority, stop and vocal variety should be paid attention to so as to make students clearly and accurately demonstrate so as to effectively improve their language expression ability. 
Therefore, university Chinese class should pay attention to reading training. At the same time, a series of oral activities such as recite, presentation, discussion and business negotiation should be carried out, which cannot only enliven the class but also make students participate in the class, helping them better understand the contents, and effectively exercising their communication and demonstration ability. For example, in modern poem Goddess Peak teaching, reading can be conducted so as to help students have a good knowledge of the beautiful mystery and fully understand the time spirit and concept of new times. Besides, a discussion with conflict of idea as the theme can be carried out.

\section{Clear the goal, carry out communication training classes based on colorful teaching methods and activities}

The teaching goal of higher vocational school is directly aimed at professional skills training. Therefore, in order to cultivate their comprehensive development in terms of knowledge, ability and quality at the same time of grasping professional ability, the Chinese class should develop in accordance with the features of higher vocational schools and break the traditional teaching model so as to fully cultivate their professional communication ability.

To begin with, traditional teaching model and approach takes lectures as the core and students are passive objectives receiving knowledge. Therefore, advanced teaching method can change students from passive objectives to positive subjects so as to make students participate in the class, which cannot only stimulate their learning enthusiasm but also train their communication demonstration skills. In teaching, teachers should take tasks as the direction and adopt group learning, discussion, lecture, achievement exhibition method and project driven to train their communication skills in the course of learning and organizing.

In addition, teachers should carefully design various teaching steps as well as class activities. For example, the class activities mentioned above enable students put their talent into full play in specific environment so as to train their communication ability. While teaching poems, poetry reading can be conducted; while teaching theatre, theatre scene performance can be adopted; while teaching papers, a discussion can be carried out. To conclude, the communication ability of students can be comprehensively trained while participating and organizing these activities.

\section{CONCLUSION}

Chinese class, as an important approach to cultivate the quality education in higher vocational school should pay attention to the comprehensive quality cultivation, especially the professional communication ability cultivation. Besides, diversified teaching models, approaches and contents should be carried out, which cannot only stick to traditional Chinese teaching but also highlight comprehensive ability cultivation to finally properly construct university Chinese class.

This paper is one of the research results of Hubei vocational education subjects the Three-dimensional mode: Research on the University Chinese Class Positioning and Teaching Model construction with Higher Vocational Characteristics (No. G2014B022).

\section{REFERENCES}

[1] Wwu Hongming, Xu Xiangyue. Vocational Communication Course [M] the People's Publishing House,2011(1)

[2] Wu Xiaoxu. Discuss on the Influence of Chinese Teaching on Normal University Students[J] Journal of Qiqihar University,2008 (11)

[3] Xie Zhixiang. The Position and Cultivation Approach of Language Ability in University Chinese Teaching [J] The Communication of Chinese Teaching, 2011（5）

[4] Ding Hui. A Study on Key Skill Training in Higher Vocational Schools [J] Modern Vocational Education Study, 2012 (6)

Author: Zhang Ting. Hunan Shaoyang, teacher of Primary Education School of Wuhan Urban Vocational College, who is mainly engaged in Chinese literature education. 